УДК 66.061.1

С.В. Харченко ${ }^{\bowtie}$

Одеська національна академія харчових технологій, вул. Канатна, 112, м. Одеса, 65039, Україна

$\checkmark$ ogah-intit@ya.ru

\title{
ЕКСПЕРИМЕНТАЛЬНЕ ДОСЛІДЖЕННЯ ВИПАРОВУВАННЯ ЧОТИРЬОХХЛОРИСТОГО ВУГЛЕЦЮ У ГАЗОВЕ СЕРЕДОВИЩЕ
}

\begin{abstract}
В роботі приведені результати експериментальних досліджень випаровування чотирьоххлористого вуглецю в різні газові середовища (азот та двоокис вуглецюю). Дослідження проводилися при тисках від атмосферного до 0,2 бар, та температурах від 15 до $30{ }^{\circ} \mathrm{C}$. В роботі приведений детальний опис експериментального стенду та особливості проведення експерименту. Отримані результати дозволяють провести апробацію математичної моделі для розрахунку тепловологісних процесів, які мають місие при холодильній обробчі харчових продуктів.

Ключові слова: Випаровування - Експериментальне дослідження - Чтотирьоххлористий вуглеиь - Температура мокрого термометра - Тепловологісний проиес
\end{abstract}

\section{С.В. Харченко}

Одесская национальная академия пищевых технологий, ул. Канатная, 112, г. Одесса, 65039, Украина

\section{ЭКСПЕРИМЕНТАЛЬНОЕ ИССЛЕДОВАНИЕ ИСПАРЕНИЯ ЧЕТЫРЕХХЛОРИСТОГО УГЛЕРОДА В ГАЗОВУЮ СРЕДУ}

\begin{abstract}
В работе приведены результаты экспериментальных исследований испарения четьреххлористого углерода в различные газовые среды (азот и диоксид углерода). Исследования проводились при давлениях от атмосферного до 0,2 бар, и температурах от 15 до $30{ }^{\circ} \mathrm{C}$. В работе приведено детальное описание экспериментального стенда и особенности проведения эксперимента. Полученные результаты позволяют провести апробацию математической модели для расчёта тепловлажностных прочессов, которые имеют место при холодильной обработке продуктов.

Ключевые слова: Испарение - Экспериментальное исследование - Четыреххлористый углерод - Температура мокрого термометра - Тепловлажностный процесс
\end{abstract}

DOI: $10.15673 / 0453-8307.4 / 2015.39285$

This work is licensed under the Creative Commons Attribution International License (CC BY). http://creativecommons.org/licenses/by/4.0/

\section{I. ВСТУП}

Питання якісного збереження харчових продуктів завжди буде актуальним. Вдосконалення наукових основ та технічних засобів дає можливість більш чітко витримувати умови зберігання харчових продуктів. Враховуючи, що усі технології збереження харчових продуктів супроводжуються масообмінними процесами, відомими як випаровування, між продуктами та газовим середовищем, в якому вони знаходяться, важливо вміти прогнозувати їх характеристики. [1, 5]

Випаровуванням називають процеси коли рідина, що випаровується або тверде тіло, що сублімує, збагачує газове середовище 3 відмінними від рідини, твердого тіла компонентами. Цей же процесс полягає в основі психрометричних явищ, кількісний опис яких становить значний практичний інтерес. Крім холодильних технологій та технологій кондиціювання повітря й випарного охолодження, явище розчинності рідин у газових середовищах та технологія газової екстракції базуються на тому ж процесі фазового перетворення рідини в пару (випаровування), 3 наступним “засвоєнням" цієї пари газовим середовищем. У випадку, коли розглядається процес випаровування води у повітря, досить часто його називають тепловологісним, таку назву використовують і в інших випадках, коли газове середовище та рідина, що випаровується (тверде тіло, що сублімує), є іншими. Доцільно підкреслити, що розчинність розглядається як випаровування рідини або сублімація твердого тіла в газове середовище змінного складу.

Ці процеси мають достатньо складний характер і відповідно мають різні підходи до їх опису. Нами була розроблена термодинамічна модель тепловологісних процесів, яка має єдиний підхід до моделювання таких процесів. Такий підхід базується на ізобарно-ізоентальпійній гіпотезі протікання процесу випаровування вологи 3 поверхні харчового продукту. В наших дослідженнях використовується більш узагальнене поняття - капілярно-пористе тіло, в порах (капілярах) якого чи на поверхні його “сухої компоненти” знаходиться вода в рідкому або твердому стані (льод). Процес 
випаровування води або сублімації льоду в повітря (стосовно холодильних технологій харчової сировини) будемо розглядати $13,92,106]$ як результат взаємодії (тепломасообміну) потоку газового середовища (зазвичай ним $є$ атмосферне повітря) 3 поверхнею капілярно-пористого тіла.

Також досить важливо врахувати, що питома теплота випаровування в тепловологісному процесі дорівнює сумі питомої теплоти фазового переходу вода-пара чи лід-пара чистих води або льоду та питомої енергії зв'язку води з “сухою компонентою” харчового продукту (капілярно-пористого тіла). Таку енергію зв'язку можна розрахувати 3 експериментальних даних по виморожуванню води під час заморожування досліджуваних об'єктів - результатом таких експериментів $є$ рівноважна доля вимороженої води при заданих від'ємних температурах. У випадку, коли мова йде про холодильну обробку харчових продуктів або харчової сировини, процес випаровування (під яким розуміють формування втрат маси від усушки) розглядається як випаровування так званої “вільної” та “слабо зв'язаної” води. Це дає можливість вважати рівною нулю енергію зв'язку води з “сухою компонентою” харчового продукту для вище зазначених процесів.

Класичним експериментом, який проведено в різних наукових лабораторіях, а його результати узгоджені на багатьох Женевських міжнародних конференціях, $\epsilon$ експеримент по визначенню різниці температур сухого та мокрого термометрів у залежності від стану атмосфери, в якій вони знаходяться. Сукупність сухого та мокрого термометрів у залежності від способу організації руху повітря відносно кульки мокрого термометра називають станційним або аспіраційним психрометрами. Якщо надійним способом виміряти барометричний тиск, то вимірювання різниці температур сухого та мокрого термометрів дозволяє розрахувати значення відносної вологості чи вологовмісту атмосферного повітря $[2,3]$. В основу такого розрахунку покладено емпіричні вирази, що апроксимують експериментальні дані по тиску насиченої пари в повітрі в залежності від барометричного тиску, температури та відносної вологості, з урахуванням коефіцієнта Пойтінга.

У плані апробації термодинамічної теорії тепловологісних процесів, виникає питання - "чи може ця модель описати закономірності формування різниці температур сухого та мокрого термометрів без апроксимації експериментальних даних, базуючись тільки на рівнянні стану вологого повітря та водяної пари?" [4]. В загальному сенсі базуючись на рівняннях стану газового середовища, в яке проходить випаровування та рівнянні стану речовини, яка випаровується.

Позитивна відповідь на це запитання може бути отримана, якщо гіпотетично вважати процес взаємодії повітря з кулькою мокрого термометру ізоентальпійним процесом. Така гіпотеза $(\Delta i=0)$ прийнята 3 похибкою до кількості теплоти, що перетікає з верхньої, більш теплої частини мокрого термометра до холодної кульки мокрого термо- метра. Крім того, цей тепловологісний процес $є$ й ізобарним.

Отримані експериментальні дані щодо різниці температур термометрів при тисках, менших 1 атм, будуть підставою для апробації можливостей розробленого експериментального стенду та методик вимірювання при таких параметрах стану газового середовища. Кінцевий результат проведення апробації розробленої термодинамічної теорії полягає у вимірюванні різниці температур та співставленні експериментальних та розрахункових даних з випаровування рідин (речовин), відмінних від води. Такими речовинами, що доступні для проведення експерименту та не киплять при кімнатних температурах і тиску 1 атм, є наприклад чотирьоххлористий вуглець.

Нами були проведені експериментальні дослідження випаровування чотирьоххлористого вуглецю $\left(\mathrm{CCL}_{4}\right)$ в різноманітні газові середовища, такі як азот, диоксид вуглецю.

\section{ІІ. ЕКСПЕРИМЕНТАЛЬНИЙ СТЕНД}

Розуміючи специфіку експерименту, його проведенню та проектуванню була приділена особлива увага. При проектуванні стенду була поставлена задача реалізувати ізобарно-ізоентальпійний процес випаровування аналогічно до аспіраційного психрометра. Принципова схема стенду зображена на рисунку 1 .

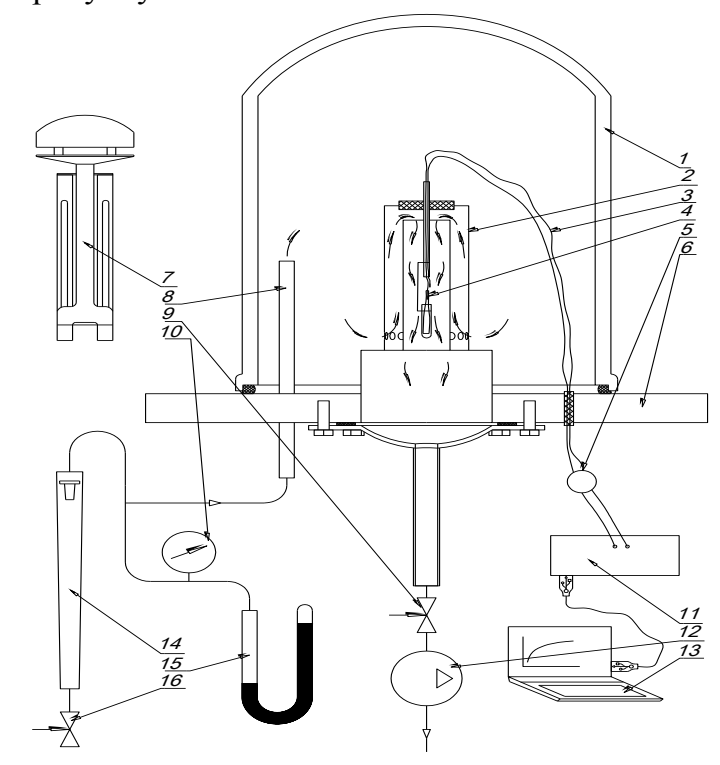

Рисунок 1 - Принциипова схема експериментального стенду.

1 - скляний резервуар (ковпак); 2 - циліндри з нержавіючої сталі; 3 - термопари; 4 - вимірювальний осередок; 5 - перемикач; 6 - металева пластина; 7 - психрометр із електромотором; 8 трубка подачі робочої речовини; 9 - вентиль "грубого" регулювання тиску; 10 - зразковий манометр; 11 - вимірювальний комплекс; 12 - вакуумний насос; 13 - комп'ютер; 14 - ротаметр; 15 інспекторський ртутний барометр; 16 - вентиль "тонкого" регулювання тиску 
Вимірювальний робочий простір представляє собою скляний резервуар (ковпак) 1 , який встановлюється на металеву пластину 6. Конструкція робочого простору дозволяє змінювати тиск від атмосферного і нижче. Гранична можливість зниження тиску в робочому просторі визначається якістю монтажу та тиском насиченої пари мастила вакуумного насоса при робочій температурі.

При проведенні експериментальних вимірів досягались значення тиску до 0,15 бар. Для створення зниженого тиску та організації циркуляції газу через робочий простір використовувався вакуумний насос 12 та два вентилі, "тонкого" регулювання 16 для зміни витрати циркулюючого газу, та "грубого" регулювання 9 для зміни рівня вакууму в робочому просторі. Робоча речовина (газ) подається через трубку 8 , яка введена через вакуумне ущільнення, до робочого простору. Між вентилем 16 і трубкою 8 підключений вимірювач об'ємної витрати робочої речовини (газу), ротаметр 14. До робочого простору підключений зразковий манометр 10 для орієнтовного виміру (контролю) тиску в робочому просторі. Точний вимір тиску проводиться інспекторським ртутним барометром 15, який дозволяе вимірювати тиск у діапазоні від 10 до 1013 мбар з похибкою 0.005 бар. У середині робочого простору розміщений вимірювальний осередок 4 д досліджуваною речовиною, яка екранована двома циліндрами 2, що виконані 3 "дзеркальної" нержавіючої сталі. Між цими циліндрами утворюється кільцевий зазор, який примушує рухатись робочу речовину лабіринтним шляхом, що додатково створює умови для термічної стабілізації потоку газа. У разі використання рідкої речовини (вода, чотирьоххлористий вуглець) використовувалась батистова тканина, якою обгортали "мокрий" термометр (термопару), якщо досліджували розчинність твердої речовини (нафталін), тоді його наплавляли безпосередньо на спай термопари. В потоці газу, що омиває робочу речовину, встановлена "суха" термопара для виміру температури газу. Також для більш точного виміру різниці температур додатково використовувалась диференціальна термопара. В якості вимірювачів температури використовувались мід-константанові термоелектричні датчики температури (термопари) 3. До вимірювального комплексу 11 термопари підключені через перемикач 6. Схема включення 3 індивідуальним холодним спаєм, який термостатований у термостаті з льодом, що тане. Повірений вимірювальний комплекс має можливість підключення до комп'ютера 13. Для виміру початкової абсолютної вологості повітря при атмосферному тиску використовувався аспіраційний психрометр із електромотором 7.

Методика проведення вимірів на експериментальному стенді полягає в наступному. У ємність заливалась досліджувана рідина, яка зволожувала (змочувала) капілярно-пористу поверхню. В ролі капілярно-пористої поверхні, як відмічалось раніше, виступала підготовлена батистова тканина. Установлювався вакуумний ковпак і включався вакуумний насос. За допомогою регулюючих вен- тилів установлювались необхідний тиск і витрата газу у вимірювальному блоці. Вимірювались температура газового середовища перед робочим осередком (сухий термометр), температура мокрого термометра і різниця температур сухого й мокрого термометрів (диференціальна термопара). Змінюючи витрати повітря знаходили район швидкостей, при яких різниця температур сухого й мокрого термометрів залишалась постійною і максимальною, й проводили вимір температур.

При проведенні експериментів температури сухого та мокрого термометрів вимірювались за допомогою термопар. Для створення умов теплообміну аналогічних стандартному аспіраційному психрометру була використана пластикова трубка, навколо якої обгорнута батистова тканина. Потім вимірювались тиск і витрати газового середовища. У випадку використання в якості робочої речовини атмосферного повітря додатково вимірювали за допомогою психрометра початкову вологість повітря на вході в установку. Якщо в якості робочої речовини використовувався азот або двоокисвуглецю, у вимірі відносної вологості не було потреби, тому що газ подавався з балонів, через редуктор, безпосередньо під вакуумний резервуар. Враховуючи способи отримання використаних в експериментах газів, в балонах 3 ними виключена наявність води, тому в таких випадках початкова відносна вологість по воді приймалась рівною нулю.

\section{III. РЕЗУЛЬТАТИ ЕКСПЕРИМЕНТАЛЬНИХ ДОСЛІДЖЕНЬ}

Експериментальне дослідження проводилося в діапазоні температур від 15 до $34{ }^{\circ} \mathrm{C}$. Необхідно більше звернути уваги на деталі створення робочого осередку. Принципова схема показана на рисунку 2.

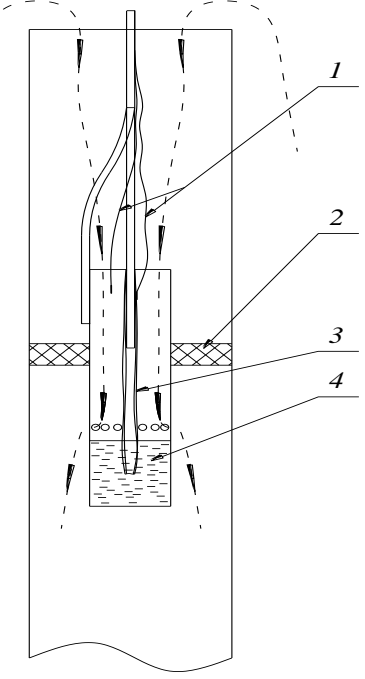

Рисунок 2 - Принципова схема робочого осередку. 1 - термопари; 2 - ущільнення; 3 - батистова тканина; 4 - досліджувана речовина; - - - - напрямок руху газового середовища. 
Особливістю конструкції є суттєве звуження живого перерізу для протікання газу. За рахунок ущільнення 2 було введено трубку меншого діаметра, тим самим зменшився живий переріз для протікання газового середовища. Ці конструктивні зміни дозволили провести експериментальні дослідження в умовах аспіраційного психрометра.

Таблиця 1 - Експериментальні дані $t_{c}$ і $t_{m}$ під час випаровування чотирьоххлористого вуглецю в середовище двоокису вуглецю при різних тисках $\left(\mathrm{CCL}_{4}\right.$ в $\left.\mathrm{CO}_{2}\right)$.

\begin{tabular}{|c|c|c|c|}
\hline $\boldsymbol{P}$ & $\boldsymbol{t}_{\boldsymbol{c}}$ & $\boldsymbol{t}_{\boldsymbol{\mu}}$ & $\boldsymbol{\Delta} \boldsymbol{t}$ \\
\hline мБар & ${ }^{\circ} \mathrm{C}$ & ${ }^{\circ} \mathrm{C}$ & ${ }^{\circ} \mathrm{C}$ \\
\hline 962 & 22,859 & 8,9 & 13,95 \\
\hline 962 & 22,96 & 8,8 & 14,16 \\
\hline 801 & 22,879 & 7,22 & 15,65 \\
\hline 799 & 22,782 & 7,1 & 15,67 \\
\hline 690 & 22,752 & 7,1 & 15,66 \\
\hline 690 & 22,96 & 7,6 & 15,36 \\
\hline 969 & 22,906 & 6,18 & 16,72 \\
\hline 698,6 & 22,906 & 6,93 & 15,98 \\
\hline 468,5 & 22,825 & 4,49 & 18,33 \\
\hline 470 & 22,879 & 4,65 & 18,23 \\
\hline 473,5 & 22,852 & 4,63 & 18,22 \\
\hline 331,5 & 22,69 & 2,04 & 20,65 \\
\hline 335 & 22,74 & 2,05 & 20,68 \\
\hline 198 & 22,5 & $-1,42$ & 23,92 \\
\hline
\end{tabular}

$t_{c}, t_{M}-$ температури сухого та мокрого термометрів відповідно, $\Delta t$ - експериментальна різниця температур між сухим та мокрим термометрами в робочому осередку.

Таблиця 2 - Експериментальні дані $t_{c}$ i $t_{м}$ під час випаровування чотирьоххлористого вуглецю в середовище азоту при різних тисках $\left(\mathrm{CCL}_{4}\right.$ в $\left.\mathrm{N}_{2}\right)$.

\begin{tabular}{|c|c|c|c|}
\hline $\boldsymbol{P}$ & $\boldsymbol{t}_{\boldsymbol{c}}$ & $\boldsymbol{t}_{\boldsymbol{M}}$ & $\boldsymbol{\Delta} \boldsymbol{t}$ \\
\hline мБар & ${ }^{\circ} \mathrm{C}$ & ${ }^{\circ} \mathrm{C}$ & ${ }^{\circ} \mathrm{C}$ \\
\hline 920 & 16,08 & 3,77 & 12,31 \\
\hline 675 & 15,73 & 1,94 & 13,8 \\
\hline 465 & 15,46 & $-0,73$ & 16,2 \\
\hline 564,25 & 15,76 & 0,83 & 14,93 \\
\hline 342,5 & 15,16 & $-2,83$ & 18,0 \\
\hline
\end{tabular}

Таблиця 3 - Експериментальні дані $t_{c}$ і $t_{м}$ під час випаровування чотирьоххлористого вуглецю в середовище азоту при різних тисках $\left(\mathrm{CCL}_{4}\right.$ в $\left.\mathrm{N}_{2}\right)$.

\begin{tabular}{|c|c|c|c|}
\hline$P$ & $t_{c}$ & $t_{M}$ & $\Delta t$ \\
\hline мБар & ${ }^{\circ} \mathrm{C}$ & ${ }^{\circ} \mathrm{C}$ & ${ }^{\circ} \mathrm{C}$ \\
\hline 935,65 & 29,84 & 16,41 & 14,43 \\
\hline 867 & 29,73 & 16,12 & 14,57 \\
\hline 761 & 29,57 & 15,35 & 15,24 \\
\hline 640 & 29,25 & 15,05 & 15,39 \\
\hline 503,7 & 28,95 & 13,51 & 16,75 \\
\hline 397 & 28,73 & 11,95 & 18,27 \\
\hline 311,8 & 28,49 & 10,43 & 19,65 \\
\hline
\end{tabular}

\section{IV. ВИСНОВКИ}

Отримані чисельні експериментальні дані по розчинності різних речовин у газове середовище різного складу дозволяють провести апробацію теоретично обгрунтованих співвідношень для розрахунку тепловологісних процесів випаровування рідини з поверхні капілярно-пористого тіла (харчової сировини чи продукту) в різних холодильних технологіях. Проведені експерименти в широкому діапазоні тисків, температур та комбінацій речовин і газових середовищ в яке проходило випаровування дають змогу комплексно провести апробацію термодинамічної моделі.

Тепловологісні процеси, що були реалізовані в експериментальному стенді - випаровування рідини з кульки мокрого термометра та сублімація твердої речовини трактувались як ізобарно - iзоентальпійні процеси в тому сенсі, що ентальпійні втрати змоченої кульки термометра за рахунок випаровування рідини у потік газового середовища компенсуються притоком теплоти від нього, а саме газове середовище вбирає в себе пару рідини (твердого тіла) в максимально можливій кількості - до досягнення відносної вологості по досліджуваній речовині, рівної одиниці.

\section{ЛІТЕРАТУРА}

1. Оніщенко В.П. Математичне моделювання тепловологісних процесів випаровування / Ю.О. Желіба, С.В. Харченко // Харчова наука і технологія. - 2013. - № 1(22). - с. 97-101.

2. ГОСТ 8.221-76. ГСИ. Влагометрия и гигрометрия. Термины и определения. - Введ. 01.01.1985. - М.: Изд-во стандартов, 1976. - 38 с.

3. ГОСТ 8.524-85. Таблицы психрометрические. Построение, содержание, расчетные соотношения. - Введ. 01.01.1985. - М.: Изд-во стандартов, 1985. $-34 \mathrm{c}$.

4. Оніщенко В.П. Експериментальне дослідження розчинності в газове середовище довільного складу / Ю.О. Желіба, М.В. Оніщенко, С.В. Харченко // Холодильна техніка і технологія. - 2012. - №3 (137). - C. 57-62.

5. Santos, J.C. Energy and exergy analysis applied to the evaporative cooling process in air washers [Text] / J.C. Santos, G.D.T. Barros, J.M. Gurgel, F. Marcondes // Int. J. Refrigeration - 2013. - Vol. 36. P. 1154-1161.

Отримана в редакції 05.06.2015, прийнята до друку 03.07.2015 


\section{S. Kharchenko ${ }^{凶}$}

Odessa National Academy of Food Technologies, 112 Kanatnaia str., Odessa, 65039, Ukraine

$\triangle$ ogah-intit@ya.ru

\section{EXPERIMENTAL STUDY OF CARBON TETRACHLORID EVAPORATION INTO A GASEOUS MEDIUM}

The results of experimental studies of carbon tetrachloride evaporation in different gas atmospheres (nitrogen and carbon dioxide) are given in the paper. The studies were conducted at pressures from atmospheric to $0.2 \mathrm{bar}$, and temperatures from 15 to $30^{\circ} \mathrm{C}$. The work contains a detailed description of the experimental stand and features of experiment conduction. The obtained results allow testing of mathematical model for calculating the heat and humidity processes that occur in the processing of the refrigeration products.

Key words: Evaporation; Experimental study; Carbon Tetrachloride; Wet bulb temperature; Heat and humidity process

\section{REFERENCES}

1. Onischenko, V.P., Zheliba, Yu.O., Kharchenko, S.V. 2013. [Mathematical modeling of thermal and humidity evaporation process]. Kharchova nauka $i$ tekhnologiya [Food Science and Technology], No. 1(22), 97-101 (in Ukrainian).

2. GOST 8.221-76. GSI. Vlagometriya I gigrometriya. Terminy i opredeleniya. Vved. 01.01.1985. M.: Izd-vo standartov, 1976, 38 p. (in Russian).

3. GOST 8.524-85. Tablitsy psikhrometricheskie. Postroenie, soderzhanie, raschetnie sootnosheniya. Vved. 01.01.1985. M.: Izd-vo standartov, 1985, 34 p. (in Russian).
4. Onischenko, V.P., Zheliba, Yu.O., Kharchenko, S.V., Onischenko, M.V. 2012. Experimental study of solubility in the gas environment of free composition. Kholodylna tekhnika ta tekhnologiya [Refrigeration engineering and technology], No.3 (137), 57-62. (in Ukrainian).

5. Santos, J.C., Barros, G.D.T., Gurgel, J.M., Marcondes, F. 2013. Energy and exergy analysis applied to the evaporative cooling process in air washers. Int. J. Refrigeration, 36(3), 1154-1161. Doi: 10.1016/j.ijrefrig.2012.12.012

Received 05 June 2015 Approved 03 July 2015 Available in Internet 30.08.2015 